\title{
Evaluation of serum lipid profile, body mass index, and waistline in Chinese patients with type 2 diabetes mellitus
}

This article was published in the following Dove Press journal:

Clinical Interventions in Aging

18 April 2016

Number of times this article has been viewed

\author{
Rongtao Cui' \\ Zhiming $\mathrm{Qi}^{2}$ \\ Lin Zhou ${ }^{2}$ \\ Zuohong $\mathrm{Li}^{2}$ \\ Qing $\mathrm{Li}^{2}$ \\ Junyong Zhang ${ }^{3}$
}

'Surgical Research, Department of Orthopedic and Trauma Surgery, Duisburg-Essen University Hospital, Essen, Germany; ${ }^{2}$ Department of Orthopedics, Dalian Central Hospital, Dalian, ${ }^{3}$ Department of Gastroenterology, Shandong Provincial Hospital, Jinan, People's Republic of China
Correspondence: Junyong Zhang

Department of Gastroenterology, Shandong Provincial Hospital,

324 Jingwuweiqi Road, Jinan 250000 ,

People's Republic of China

$\mathrm{Tel}+86$ I35 83 I7 3280

Email zhangjunyong32I@outlook.com
Objective: People with type 2 diabetes are at an increased risk of hypertension, arteriosclerosis, heart disease, and stroke. Glucose intolerance (insulin resistance) is the main feature of type 2 diabetes. Obesity leads to insulin resistance, dyslipidemia, etc. The aim of this study was to assess the biochemical parameters and measures of obesity in type 2 diabetes mellitus (T2DM).

Methods: A total of 2,273 males and 6,547 females previously healthy volunteers (aged 41-95 years old) were recruited by open invitation. The basic information, including age, sex, height, weight, body mass index (BMI), waistline, hipline, menstrual cycle, and medical history, was collected by questionnaire survey and physical examination. Serum lipid profile, liver transaminase, blood glucose, postprandial blood glucose, and hemoglobin A1c were obtained after 12 hours of fasting.

Results: According to our results, diabetic patients presented serum lipid abnormality. Elevated triglyceride (TG) levels ( $\geq 1.7 \mathrm{mmol} / \mathrm{L}$ ) were noted in $19.69 \%$ of males and $20.40 \%$ of females, and reduced high-density lipoprotein cholesterol (HDL-C) levels $(\leq 1.15 \mathrm{mmol} / \mathrm{L})$ were noted in $21.96 \%$ of males and $15.74 \%$ of females. The combination of elevated TG and reduced HDL-C was the most prevalent of the combined lipid abnormalities. In contrast, no differences were observed in the levels of low-density lipoprotein cholesterol and total cholesterol. Moreover, there were statistically significant differences in the levels of BMI and waistline between T2DM and non-T2DM participants. After adjustment for BMI, logistic regression analysis revealed that the subjects with BMI $\leq 20 \mathrm{~kg} / \mathrm{m}^{2}$ and $>30 \mathrm{~kg} / \mathrm{m}^{2}$ had a significantly elevated hazard ratio of T2DM compared with participants having a BMI range of $20-30 \mathrm{~kg} / \mathrm{m}^{2}$ in both males and females. However, there was a significant difference between T2DM patients and non-T2DM patients in waistline $\left(\chi^{2}=8.57, P<0.001\right)$ than in BMI parameter $\left(\chi^{2}=6.29, P<0.001\right)$.

Conclusion: The present study shows for the first time that low levels of HDL-C, high levels of TG, and abnormal levels in BMI and waistline increase the risk of type 2 T2DM in Chinese people.

Keywords: risk assessment, body mass index, waistline, HDL-C, TG, T2DM

\section{Introduction}

Type 2 diabetes mellitus (T2DM) is a well-known disease in both developing and developed countries. In addition to being a chronic disease, obesity is a key risk factor for T2DM, cardiovascular disease (CVD), hypertension, respiratory disease, and other chronic noninfectious diseases and is becoming an important global public health problem that leads to disability, which adversely affects the individual's quality of life and increases his or her financial burden on the state. ${ }^{1-3}$ Even the prevalence of obesity in the People's Republic of China is not as high as that in developed countries; 
however, in recent years, it has shown an epidemic trend, and obesity-related metabolic syndrome in the People's Republic of China has received widespread attention. ${ }^{4}$

To account for the correlation between obesity and T2DM, body mass index (BMI) has been introduced as a composite covariate for adjustment in T2DM studies. BMI is obtained by dividing weight by the square of height (ie, $\mathrm{kg} / \mathrm{m}^{2}$ ). In developed countries, subjects with a BMI $\geq 25 \mathrm{~kg} / \mathrm{m}^{2}$ are defined as overweight and those with a BMI $\geq 30 \mathrm{~kg} / \mathrm{m}^{2}$ are defined as obese, and there are good associations and positive predictive effects between BMI and obesity-related chronic diseases. ${ }^{5,6}$ Even though BMI captures the degree of overweight and obesity, it ignores body fat distribution. Visceral fat tissue is metabolically more active than nonvisceral fat and secretes more hormones and cytokines, which might be important for the development of diabetes. ${ }^{7,8}$ It is a simple way to assess the levels of visceral fat using the measurement of waistline. ${ }^{9}$

However, it is also reported that most patients with type 2 diabetes could have dyslipidemia at varying degrees, characterized by increased levels of triglyceride (TG) and decreased serum high-density lipoprotein cholesterol (HDL-C). When this characteristic lipid profile is seen in T2DM, it is referred to as diabetic dyslipidemia and confers a risk of CVD. Insulin resistance and T2DM are generally accompanied by low levels of HDL-C and high TG. ${ }^{10-12}$

Both obesity and dyslipidemia are closely related to T2DM and share a common pathogenesis associated with "insulin resistance". However, the association between serum lipid profile, BMI, and T2DM has not been assessed simultaneously in both Chinese men and women. We aimed to investigate this relationship and make an evaluation of the serum lipid profile and BMI in Chinese patients with $\mathrm{T} 2 \mathrm{DM}$ in this setting.

\section{Methods}

\section{Subjects}

A total of 10,300 subjects (2,665 males and 7,635 females aged 40-95 years) who voluntarily requested to be hospitalized for a 2-day complete physical check-up during 2012-2015 were enrolled in this study. The exclusion criteria for the present study were as follows: type 1 diabetes mellitus (DM), noninsulin-dependent DM, severe scoliosis, polio, hyper- or hypothyroidism, impaired renal function, significant chronic lung disease, apparently abnormal liver function, rheumatoid arthritis or collagen disease, malignancies, or a history of alcoholism, heavy smoking ( $>1$ pack/d), hysterectomy, estrogen use, oophorectomy, and corticosteroid use. Finally, 2,273 healthy males aged $41-95$ years (median 60 years) and
6,547 healthy females aged 41-95 years (median 57 years) were classified to be eligible for the present study. All the subjects came from a local population of Dalian city, which is located in the northern part of the People's Republic of China. All the study subjects belonged to the Han Chinese ethnic group, which comprises $\sim 90 \%$ of the total population of the People's Republic of China. Before entering the project, all subjects signed informed consent documents, and the protocols for the study were reviewed and approved by the Ethics Committee of the Dalian Central Hospital (Dalian, People's Republic of China). For each study subject, basic information, including age, sex, family history, inheritance history, and medical history, was obtained from self-administered questionnaires. The menstrual history of each woman was recorded during an individual interview. Menopause was defined as the absence of any menstrual cycle for at least 1 year. Height, weight, waistline, and hipline were measured during the interview, with subjects wearing light indoor clothes without shoes.

\section{Laboratory measurement}

The biochemical parameters, including fasting blood glucose (FBG), postprandial blood glucose (PBG), hemoglobin A1c (HbA1c), total cholesterol (TC), TG, and serum HDL-C, were measured using an Abbott Diagnostics C8000i autoanalyzer (Abbott Laboratories, Abbott Park, IL, USA) with commercial kits. Multigent direct assays were used to estimate serum low-density lipoprotein cholesterol (LDL-C) levels (Abbott Laboratories). The whole measurement procedure was supported by the Department of Clinical Laboratory in the hospital. As a test of the Abbott Diagnostics C8000i autoanalyzer and multigent direct assay's precision, we measured blood from 15 individuals twice on the same day. The coefficient of variation for these subjects was $0.5 \%$ for FBG, $1.1 \%$ for PBG, $0.9 \%$ for $\mathrm{HbA} 1 \mathrm{c}, 0.7 \%$ for $\mathrm{TC}, 1.2 \%$ for TG, $2.0 \%$ for HDL-C, and $1.5 \%$ for LDL-C.

\section{Diagnosis criteria}

$\mathrm{FBG}>7.0 \mathrm{mmol} / \mathrm{L}, \mathrm{PBG}>11.1 \mathrm{mmol} / \mathrm{L}$, and $\mathrm{HbA} 1 \mathrm{c}>6.5 \%$ were used as the diagnosis criteria for T2DM. Subjects with a BMI $\geq 25 \mathrm{~kg} / \mathrm{m}^{2}$ were defined as overweight and those with a BMI $\geq 30 \mathrm{~kg} / \mathrm{m}^{2}$ were defined as obese.

\section{Statistical analysis}

Continuous variables were defined using median values and interquartile ranges ( 25 th to 75 th percentile) because they were not normally distributed. According to the China Adult Dyslipidemia Prevention Guide, variables were categorized as follows. We divided subjects into groups 
using stratified BMI levels. Subjects were classified by BMI into $\leq 17.5 \mathrm{~kg} / \mathrm{m}^{2}, 17.5-20 \mathrm{~kg} / \mathrm{m}^{2}, 20-22.5 \mathrm{~kg} / \mathrm{m}^{2}$, $22.5-25 \mathrm{~kg} / \mathrm{m}^{2}, 25-27.5 \mathrm{~kg} / \mathrm{m}^{2}, 27.5-30 \mathrm{~kg} / \mathrm{m}^{2}, 30-32.5 \mathrm{~kg} / \mathrm{m}^{2}$, and $>32.5 \mathrm{~kg} / \mathrm{m}^{2}$. BMI of $22.5-25 \mathrm{~kg} / \mathrm{m}^{2}$ group was used as the reference to calculate hazard ratios (HRs) with $95 \%$ confidence intervals (CIs); HDL-C $\leq 1.15 \mathrm{mmol} / \mathrm{L}(1.54 \mathrm{mmol} / \mathrm{L}$ in males), $\geq 1.16 \mathrm{mmol} / \mathrm{L}(1.55 \mathrm{mmol} / \mathrm{L}$ in males $)$; LDL-C $<3.1 \mathrm{mmol} / \mathrm{L}, \geq 3.1 \mathrm{mmol} / \mathrm{L} ; \mathrm{TC} \leq 2.8 \mathrm{mmol} / \mathrm{L}$, 2.8-5.17 mmol/L, $\geq 5.17 \mathrm{mmol} / \mathrm{L}$; and $\mathrm{TG} \leq 0.56 \mathrm{mmol} / \mathrm{L}$, $0.56-1.7 \mathrm{mmol} / \mathrm{L}, \geq 1.7 \mathrm{mmol} / \mathrm{L}$. For comparison of two unpaired groups, unpaired $t$-test was used for data that follow normal distribution and homogeneity of variances. Homogeneity of variances was tested using Levene's test. In case data were not normally distributed, nonparametric tests were used. Mann-Whitney and Kruskal-Wallis tests, respectively, were used for comparing two groups and more than two groups simultaneously. Groups for categorical variables were analyzed by chi-square or Fisher's exact tests. Logistic regression was used to explore the risk factors of T2DM. The Statistical Package for the Social Sciences software (Version 21.0; IBM Corporation, Armonk, NY, USA) was used for statistical analysis. Statistical significance was accepted for a $P$-value of 0.05 .

\section{Results}

Basic characteristics of the subjects and a comparison between males and females are listed in Table 1. Significant differences $(P<0.001)$ in age, height, weight, BMI, waistline, hipline, FBG, PBG, creatinine, HDL-C, LDL-C, TC, alanine transaminase, aspartate aminotransferase, and glutamyltranspetidase were found between males and females.

According to the criteria, males and females were classified into two groups (diabetic and nondiabetic participants), and their characteristics are presented in Table 2. Significant differences between diabetic and normal groups were found. The basic characteristics, including age, weight, BMI, waistline, FBG, PBG, HDL-C, and $\mathrm{HbA} 1 \mathrm{c}$, had significant differences between diabetic and normal subjects. Here we found that diabetic patients had lower levels of HDL-C but higher levels of TG compared with nondiabetic participants. There was a strong relation between diabetic patients and nondiabetic subjects in waistline $\left(\chi^{2}=8.57, P<0.001\right)$ than in BMI $\left(\chi^{2}=6.29, P<0.001\right)$.

Furthermore, after adjustment for BMI, logistic regression analysis revealed that the subjects of BMI $\leq 20 \mathrm{~kg} / \mathrm{m}^{2}$ and $>30 \mathrm{~kg} / \mathrm{m}^{2}$ had significantly elevated HR of diabetes compared with subjects having $20-30 \mathrm{~kg} / \mathrm{m}^{2}$ in both males (BMI $\leq 17.5 \mathrm{~kg} / \mathrm{m}^{2}$ : HR 1.524, $P<0.05$; BMI $17.5-20 \mathrm{~kg} / \mathrm{m}^{2}$ : HR 1.557, $P<0.05$; BMI $30-32.5 \mathrm{~kg} / \mathrm{m}^{2}$ : HR 1.669, $P<0.05$; BMI $>32.5 \mathrm{~kg} / \mathrm{m}^{2}$ : HR $\left.2.085, P<0.05\right)$ and females (BMI $\leq 17.5 \mathrm{~kg} / \mathrm{m}^{2}$ : HR 2.832, $P<0.05$; BMI $17.5-20 \mathrm{~kg} / \mathrm{m}^{2}$ : HR 2.794, $P<0.05$; BMI $30-32.5 \mathrm{~kg} / \mathrm{m}^{2}$ : HR 2.507, $P<0.05$; BMI $>32.5 \mathrm{~kg} / \mathrm{m}^{2}$ : HR 3.442, $P<0.05$, Figure $\left.1 \mathrm{~A}\right)$. Among adults older than 65 years, both those with BMI $\leq 20 \mathrm{~kg} / \mathrm{m}^{2}$ and $>30 \mathrm{~kg} / \mathrm{m}^{2}$ had a significantly elevated HR of diabetes compared with participants having $20-30 \mathrm{~kg} / \mathrm{m}^{2}$ (Figure 1B).

Table I Basic characteristic of the subjects

\begin{tabular}{|c|c|c|c|c|}
\hline Parameter & Males $(n=2,273)$ & Females $(n=6,547)$ & $\chi^{2}$ & $P$-value \\
\hline Age (years) & $60(55-67)$ & $57(53-63)$ & $|4.5|$ & $<0.001$ \\
\hline Height (cm) & $169(165-173)$ & $158(154.5-162)$ & 56.47 & $<0.001$ \\
\hline Weight (kg) & 7I (64-79) & $63(58-70)$ & 25.81 & $<0.001$ \\
\hline BMI $\left(\mathrm{kg} / \mathrm{m}^{2}\right)$ & $25.09(22.74-27.18)$ & $25.26(23.07-27.69)$ & 5.01 & $<0.001$ \\
\hline Waistline (cm) & $92(88-100)$ & $89(82-95)$ & 20.37 & $<0.001$ \\
\hline Hipline $(\mathrm{cm})$ & $102(98-106)$ & $100(95-105)$ & 11.58 & $<0.001$ \\
\hline $\mathrm{FBG}(\mathrm{mmol} / \mathrm{L})$ & $5.87(5.4 I-6.89)$ & $5.6 I(5.24-6.21)$ & 13.87 & $<0.001$ \\
\hline PBG (mmol/L) & $7.72(6.15-11.03)$ & $7.2(6.05-9.36)$ & 6.00 & $<0.001$ \\
\hline Creatinine $(\mu \mathrm{mol} / \mathrm{L})$ & $73(67.4-82.5)$ & $6 \mathrm{I} .4(56.7-67)$ & 46.35 & $<0.001$ \\
\hline HDL-C (mmol/L) & $1.22(1.06-1.44)$ & $1.39(1.21-1.61)$ & 22.02 & $<0.001$ \\
\hline LDL-C (mmol/L) & $3.12(2.57-3.68)$ & $3.3(2.74-3.89)$ & 8.37 & $<0.001$ \\
\hline TC (mmol/L) & $5.16(4.5 I-5.83)$ & $5.52(4.85-6.21)$ & 14.60 & $<0.001$ \\
\hline $\mathrm{TG}(\mathrm{mmol} / \mathrm{L})$ & $1.29(0.92-1.89)$ & $1.27(0.92-1.82)$ & 1.51 & 0.13 \\
\hline ALT (U/L) & $18(13-24)$ & $16(12-22)$ & 8.18 & $<0.001$ \\
\hline AST (IU/L) & $22(18-26)$ & $21(18-25)$ & 3.40 & $<0.001$ \\
\hline GT (IU/L) & $30(2 \mid-46)$ & $21(15-30)$ & 26.73 & $<0.001$ \\
\hline HbAlc (\%) & $5.8(5.5-6.2)$ & $5.8(5.6-6.2)$ & 0.05 & 0.96 \\
\hline
\end{tabular}

Notes: Data are presented as median with interquartile range. $\chi^{2}$ value is the result of Mann-Whitney test between males and females. $P<0.05$ was considered statistically significant.

Abbreviations: BMI, body mass index; FBG, fasting blood glucose; PBG, postprandial blood glucose; HDL-C, high-density lipoprotein cholesterol; LDL-C, low-density lipoprotein cholesterol; TC, total cholesterol; TG, triglyceride; ALT, alanine transaminase; AST, aspartate aminotransferase; GT, glutamyltranspetidase; HbAI c, glycosylated hemoglobin. 
Table 2 Frequency of the BMI, waistline, FBG, PBG, lipid profile, and HbAIc in all subjects with and without diabetes

\begin{tabular}{|c|c|c|c|c|}
\hline Parameter & Diabetes $(n=1,336)$ & Nondiabetes $(n=7,484)$ & $x^{2}$ & $P$-value \\
\hline Age (years) & $61(55-68)$ & $58(53-63)$ & 11.87 & $<0.001$ \\
\hline Height (cm) & $160(155-166)$ & $161(156-166)$ & 2.04 & 0.04 \\
\hline Weight (kg) & $67(59-74)$ & $65(58-72)$ & 4.44 & $<0.001$ \\
\hline BMI $\left(\mathrm{kg} / \mathrm{m}^{2}\right)$ & $25.88(23.59-28.12)$ & $25 . I(22.9 I-27.4 I)$ & 6.29 & $<0.001$ \\
\hline Waistline $(\mathrm{cm})$ & $94(85-100)$ & $90(83-96)$ & 8.57 & $<0.001$ \\
\hline Hipline (cm) & $101(97-106)$ & $100(96-105)$ & 5.47 & $<0.001$ \\
\hline FBG (mmol/L) & $7.56(5.88-9.79)$ & $5.59(5.24-6.07)$ & 33.22 & $<0.001$ \\
\hline PBG (mmol/L) & I3.43 (8.36-18.19) & $7.04(5.94-8.77)$ & 34.61 & $<0.001$ \\
\hline Creatinine $(\mu \mathrm{mol} / \mathrm{L})$ & $65.5(59.9-73)$ & $63.7(58-70.9)$ & 7.14 & $<0.001$ \\
\hline HDL-C (mmol/L) & $1.27(1.1-1.5)$ & $1.36(1.18-1.58)$ & 9.37 & $<0.001$ \\
\hline LDL-C (mmol/L) & $3.24(2.64-3.88)$ & $3.25(2.7-3.83)$ & 0.53 & 0.60 \\
\hline $\mathrm{TC}(\mathrm{mmol} / \mathrm{L})$ & $5.44(4.73-6.15)$ & $5.42(4.76-6.12)$ & 0.11 & 0.91 \\
\hline TG $(\mathrm{mmol} / \mathrm{L})$ & $1.45(1.01-2.07)$ & $1.25(0.9-1.79)$ & 8.52 & $<0.001$ \\
\hline $\mathrm{ALT}(\mathrm{U} / \mathrm{L})$ & $17(13-24)$ & $16(12-23)$ & 5.31 & $<0.001$ \\
\hline AST (IU/L) & $21(17-25)$ & $21(18-26)$ & 4.63 & $<0.001$ \\
\hline GT (IU/L) & $24(17-35)$ & $22(16-34)$ & 4.20 & $<0.001$ \\
\hline HbAIc (\%) & $6.7(5.8-8.1)$ & $5.8(5.5-6.1)$ & 30.84 & $<0.001$ \\
\hline
\end{tabular}

Notes: Data are presented as median with interquartile range. $\chi^{2}$ value is the result of Mann-Whitney test between diabetic and nondiabetic participants. $P<0.05$ was considered statistically significant.

Abbreviations: BMI, body mass index; FBG, fasting blood glucose; PBG, postprandial blood glucose; HbAlc, glycosylated hemoglobin; HDL-C, high-density lipoprotein cholesterol; LDL-C, low-density lipoprotein cholesterol; TC, total cholesterol; TG, triglyceride; ALT, alanine transaminase; AST, aspartate aminotransferase; GT, glutamyltranspetidase.

After serum lipid was adjusted, Mann-Whitney and Kruskal-Wallis tests in Table 3 showed that diabetes was more prevalent in the class of lower HDL-C values (males: $\leq 1.15 \mathrm{mmol} / \mathrm{L}$; females: $\leq 1.54 \mathrm{mmol} / \mathrm{L}$ ) in both males and females. However, diabetes was more prevalent in the class of higher TG levels ( $\geq 1.7 \mathrm{mmol} / \mathrm{L})$ in females; no significant correlation between diabetes and TG was found in males. In this study, no relationships were found between LDL-C, TC levels, and diabetes. When a logistic regression analysis was performed with the presence of $\mathrm{T} 2 \mathrm{DM}$ as a dependent variable, males with HDL-C levels $\leq 1.15 \mathrm{mmol} / \mathrm{L}$ and females with HDL-C levels $\leq 1.54 \mathrm{mmol} / \mathrm{L}$ were found to be associated with the presence of T2DM (males: odds ratio $1.64,95 \% \mathrm{CI} 1.17-2.34, P<0.01$; females: odds ratio $1.92,95 \%$ CI $0.92-2.05, P<0.01)$ compared with HDL-C levels $\geq 1.16 \mathrm{mmol} / \mathrm{L}$ in males and $\geq 1.55 \mathrm{mmol} / \mathrm{L}$ in females even after adjusting for sex, age, height, weight, BMI, waistline, and serum creatinine levels (Table 4). We also found that a high TG level was also associated with the presence of T2DM (males: odds ratio $1.02,95 \%$ CI $0.74-2.02, P<0.05$; females: odds ratio $2.33,95 \%$ CI $0.67-2.39, P<0.05)$.

In both sexes, the correlation $(r=-0.350$ in males, $r=-0.352$ in females) between DM and FBG was higher than that between DM and other impact factors. Even both body
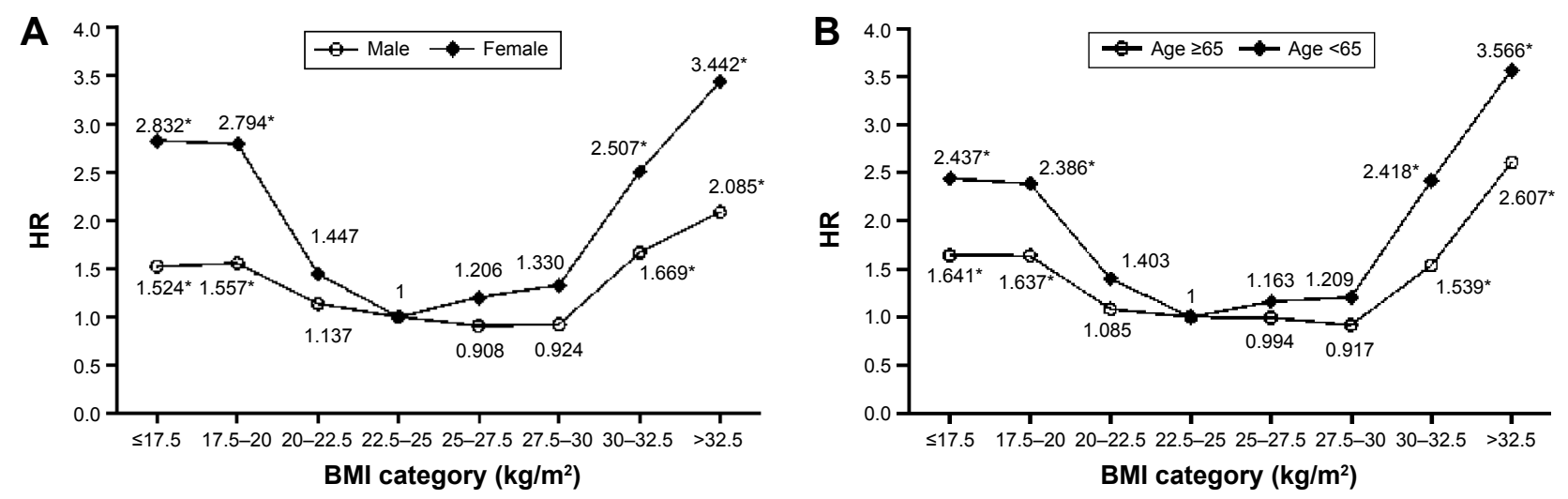

Figure I Comparison of BMI $\left(\mathrm{kg} / \mathrm{m}^{2}\right)$ category-related HR changes between $(\mathbf{A})$ males and females and $(\mathbf{B})$ participants aged $\geq 65$ and $<65$ years. Notes: BMI of $22.5-25 \mathrm{~kg} / \mathrm{m}^{2}$ group was used as the reference to calculate HRs with $95 \% \mathrm{Cls}$. $* \mathrm{P}<0.05$ compared to BMl $22.5-25 \mathrm{~kg} / \mathrm{m}^{2}$. $\mathrm{P}<0.05$ was considered statistically significant.

Abbreviations: $\mathrm{BMI}$, body mass index; $\mathrm{HR}$, hazard ratio; $\mathrm{Cl}$, confidence interval. 
Table 3 The incidence of diabetes in the stratified lipid profile levels

\begin{tabular}{|c|c|c|c|c|}
\hline Parameter & $\mathbf{n}$ & Diabetes (\%) & $x^{2}$ & $P$-value \\
\hline \multicolumn{5}{|l|}{ Males } \\
\hline HDL-C (mmol/L) & & & 22.75 & $<0.00$ I \\
\hline$<1.15$ & 879 & 21.96 & & \\
\hline$>1.16$ & 1,394 & 14.20 & & \\
\hline LDL-C (mmol/L) & & & 0.32 & 0.57 \\
\hline$<3.1$ & 1,110 & 17.66 & & \\
\hline$\geq 3.1$ & 1,163 & 16.77 & & \\
\hline $\mathrm{TC}(\mathrm{mmol} / \mathrm{L})$ & & & $-|.5|$ & 0.13 \\
\hline$\leq 2.8$ & 8 & 25.00 & & \\
\hline $2.8-5.17$ & 1,135 & 18.33 & & \\
\hline$\geq 5.17$ & 1,130 & 16.02 & & \\
\hline TG (mmol/L) & & & -1.87 & $<0.05$ \\
\hline$\leq 0.56$ & 95 & 17.89 & & \\
\hline $0.56-1.7$ & $\mathrm{I}, 477$ & 15.98 & & \\
\hline$\geq 1.7$ & 701 & 19.69 & & \\
\hline \multicolumn{5}{|l|}{ Females } \\
\hline HDL-C (mmol/L) & & & 20.19 & $<0.001$ \\
\hline$<1.54$ & 4,531 & 15.74 & & \\
\hline$>1.55$ & 2,016 & $\mid \mathrm{I} .5 \mathrm{I}$ & & \\
\hline LDL-C (mmol/L) & & & 0.20 & 0.65 \\
\hline$<3.1$ & 2,669 & 14.20 & & \\
\hline$\geq 3.1$ & 3,878 & 14.60 & & \\
\hline $\mathrm{TC}(\mathrm{mmol} / \mathrm{L})$ & & & -1.29 & 0.20 \\
\hline$\leq 2.8$ & 18 & 0.00 & & \\
\hline $2.8-5.17$ & 2,322 & 13.82 & & \\
\hline$\geq 5.17$ & 4,207 & 14.83 & & \\
\hline $\mathrm{TG}(\mathrm{mmol} / \mathrm{L})$ & & & -8.96 & $<0.00$ I \\
\hline$\leq 0.56$ & 235 & 8.09 & & \\
\hline $0.56-1.7$ & 4,400 & 12.18 & & \\
\hline$\geq 1.7$ & 1,912 & 20.40 & & \\
\hline
\end{tabular}

Notes: Data are presented as number and percentage of each category. $P$-values of $\chi^{2}$ results from Mann-Whitney and Kruskal-Wallis tests are presented. $P<0.05$ was considered statistically significant.

Abbreviations: HDL-C, high-density lipoprotein cholesterol; LDL-C, low-density lipoprotein cholesterol; TC, total cholesterol; TG, triglyceride.

weight and BMI were positively correlated with diabetes. The correlation $(r=-0.56)$ between DM and BMI in both males and females was higher than that between DM and body weight $(r=-0.48)$. The result showed that the correlation $(r=-0.080)$ between DM and waistline in both males and females was higher than that between DM and BMI $(r=-0.073)$. HDL-C ( $r=0.105$ in males, $r=0.091$ in females) and TG ( $r=-0.043$ in males, $r=-0.108$ in females) were correlated with DM in both males and females. These relationships are shown in Table 5.

\section{Discussion}

The global population is currently undergoing an upward shift in its age structure due to decreasing fertility rate and increasing life expectancy. Meanwhile, the incidence of
T2DM is increasing sharply and is becoming a serious public health problem. We investigated the relationship between BMI, waistline, and blood lipid profiles with T2DM to improve its diagnosis and prevention and reduce not only a significant economic and societal burden but also a social burden on individuals. ${ }^{13}$

Standards for the definition of obesity using BMI in western countries and the Asia-Pacific region are not the same. A previous study showed that relative risk of T2DM predicted by BMI was 1.18 (95\% CI 1.16-1.20), which increased with increasing BMI. ${ }^{14,15} \mathrm{BMI}$ and waistline serve as parameters to estimate general and abdominal fat masses, respectively. It is well known that the abdominal fat mass is of particular importance in the development of not only T2DM but also other chronic diseases, including CVDs and some forms of cancer. ${ }^{16,17}$ A previous study in Germany has found high prevalence for obesity $(23.9 \%)$ and increased waistline (39.5\%; males $>102 \mathrm{~cm}$, females $>88 \mathrm{~cm}) .{ }^{18}$ However, there is a strong relation between the two parameters, and the terms "general" and "abdominal" obesity are not mutually exclusive but designate overlapping fat compartments. It is well known that waistline is a more exact measure of visceral fat in individuals. At the same time, increased waistline also has a high correlation with T2DM, which was found in our present study. Moreover, our present study found that excessively high or low levels of BMI have high correlation with T2DM, which further resulted to testify the discovery from Kuo et al. ${ }^{19}$ In males, there were no significant differences between BMI and waistline in T2DM. On the contrary, waistline had higher correlation with T2DM than BMI in Chinese females. There was a significant difference between DM patients and non-DM subjects in waistline $\left(\chi^{2}=8.57, P<0.001\right)$ than in BMI parameter $\left(\chi^{2}=6.29, P<0.001\right)$.

A previous study concluded that persons with impaired glucose tolerance and T2DM have hypertriglyceridemia and increased HDL catabolism, which result in decreasing levels of HDL. ${ }^{20}$ Many potential mechanisms could explain the inverse correlation between the hypertriglyceridemia of insulin-resistant states and increased HDL catabolism, leading to low plasma HDL concentrations. One possibility may be a reduction in lipoprotein lipase (LPL) activity, which would have the effect of impairing the maturation of HDL particles. The normal insulin-mediated stimulation of LPL activity has been shown to be blunted in insulin resistance. ${ }^{21}$ In T2DM, particularly when glycemic control is poor in patients who are relatively insulin deficient, LPL activity is reduced..$^{22}$ Organs and tissues with lower blood glucose (BG) include the liver, adipose tissue, and muscle, and the liver is a key organ in 
Table 4 Logistic regression of T2DM

\begin{tabular}{|c|c|c|c|c|c|c|}
\hline \multirow[t]{2}{*}{ Parameter } & \multicolumn{3}{|c|}{ Unadjusted } & \multicolumn{3}{|l|}{ Adjusted } \\
\hline & OR & $95 \% \mathrm{Cl}$ & $P$-value & OR & $95 \% \mathrm{Cl}$ & $P$-value \\
\hline \multicolumn{7}{|l|}{ Males } \\
\hline \multicolumn{7}{|c|}{ HDL-C (mmol/L) } \\
\hline$\leq \mathrm{I} .15$ & $\mathrm{I} .00$ (ref) & & & $\mathrm{I} .00$ (ref) & & \\
\hline$\geq 1.16$ & 1.57 & $1.12-1.66$ & 0.007 & 1.64 & I. $17-2.34$ & 0.006 \\
\hline \multicolumn{7}{|c|}{ LDL-C (mmol/L) } \\
\hline$<3.1$ & $\mathrm{I} .00$ (ref) & & & $\mathrm{I} .00$ (ref) & & \\
\hline$\geq 3.1$ & 0.86 & $0.29-1.59$ & 0.794 & 0.91 & $0.34-2.36$ & 0.910 \\
\hline \multicolumn{7}{|l|}{$\mathrm{TC}(\mathrm{mmol} / \mathrm{L})$} \\
\hline$\leq 2.8$ & 1.00 (ref) & & & $\mathrm{I} .00$ (ref) & & \\
\hline $2.8-5.17$ & $\mathrm{I} .43$ & $0.68-3.55$ & & 1.27 & $0.39-3.11$ & \\
\hline$\geq 5.17$ & 1.03 & $0.44-2.73$ & 0.960 & 0.99 & $0.26-2.51$ & 0.739 \\
\hline \multicolumn{7}{|c|}{ TG (mmol/L) } \\
\hline$\leq 0.56$ & 1.00 (ref) & & & $\mathrm{I} .00$ (ref) & & \\
\hline $0.56-1.7$ & 1.55 & $0.89-2.98$ & & 1.63 & $0.97-3.34$ & \\
\hline$\geq 1.7$ & 1.00 & $0.66-1.75$ & 0.017 & 1.02 & $0.74-2.02$ & 0.011 \\
\hline \multicolumn{7}{|l|}{ Females } \\
\hline \multicolumn{7}{|c|}{ HDL-C (mmol/L) } \\
\hline$\leq \mathrm{I} .54$ & $\mathrm{I} .00$ (ref) & & & $\mathrm{I} .00$ (ref) & & \\
\hline$\geq 1.55$ & 1.83 & $1.05-1.94$ & 0.005 & 1.92 & $0.92-2.05$ & 0.003 \\
\hline \multicolumn{7}{|c|}{ LDL-C (mmol/L) } \\
\hline$<3.1$ & $\mathrm{I} .00$ (ref) & & & $\mathrm{I} .00$ (ref) & & \\
\hline$\geq 3.1$ & 1.18 & $0.9-1.54$ & 0.222 & 1.18 & $0.89-1.56$ & $0.24 I$ \\
\hline \multicolumn{7}{|c|}{$\mathrm{TC}(\mathrm{mmol} / \mathrm{L})$} \\
\hline$\leq 2.8$ & $\mathrm{I} .00$ (ref) & & & $\mathrm{I} .00$ (ref) & & \\
\hline $2.8-5.17$ & 0.91 & $0.61-1.38$ & & 0.85 & $0.64-1.44$ & \\
\hline$\geq 5.17$ & 0.97 & $0.78-1.59$ & 0.870 & 1.00 & $0.86-1.62$ & 0.760 \\
\hline \multicolumn{7}{|c|}{ TG (mmol/L) } \\
\hline$\leq 0.56$ & 1.00 (ref) & & & $\mathrm{I} .00$ (ref) & & \\
\hline $0.56-1.7$ & 1.94 & $0.93-2.35$ & & 2.05 & $0.8 I-2.56$ & \\
\hline$\geq 1.7$ & 2.27 & $0.70-2.31$ & 0.014 & 2.33 & $0.67-2.39$ & 0.013 \\
\hline
\end{tabular}

Notes: Adjustment for sex, age, height, weight, BMI, waistline, hipline, and serum creatinine levels. $P<0.05$ was considered statistically significant.

Abbreviations: OR, odds ratio; $\mathrm{Cl}$, confidence interval; HDL-C, high-density lipoprotein cholesterol; LDL-C, low-density lipoprotein cholesterol; TC, total cholesterol; TG, triglyceride; BMI, body mass index; T2DM, type 2 diabetes mellitus.

Table 5 Correlation coefficients among age, height, weight, BMI, waistline, hipline, FBG, HDL, LDL, TC, TG, and DM in males and females

\begin{tabular}{|c|c|c|c|c|c|c|c|c|c|c|c|c|}
\hline Parameter & DM & Height & Weight & BMI & Waistline & Hipline & FBG & HDL & LDL & TC & TG & Age \\
\hline DM & & 0.022 & $-0.48^{a}$ & $-0.56^{b}$ & $-0.53^{\mathrm{a}}$ & -0.039 & $-0.350^{\mathrm{b}}$ & $0.105^{b}$ & 0.016 & 0.036 & $-0.043^{\mathrm{a}}$ & $-0.064^{b}$ \\
\hline Height & $0.067^{b}$ & & $0.194^{b}$ & $-0.244^{b}$ & $0.190^{\mathrm{b}}$ & $0.244^{b}$ & 0.006 & $-0.052^{\mathrm{a}}$ & -0.006 & -0.002 & $0.056^{\mathrm{b}}$ & $-0.283^{b}$ \\
\hline Weight & $-0.035^{b}$ & $0.332^{\mathrm{b}}$ & & $0.873^{b}$ & $0.352^{\mathrm{b}}$ & $0.377^{b}$ & $0.105^{b}$ & $-0.168^{\mathrm{b}}$ & 0.033 & 0.016 & $0.180^{\mathrm{b}}$ & $-0.085^{b}$ \\
\hline BMI & $-0.073^{b}$ & $-0.150^{\mathrm{b}}$ & $-0.858^{b}$ & & $0.353^{b}$ & $0.354^{b}$ & $0.126^{\mathrm{b}}$ & $-0.176^{\mathrm{b}}$ & 0.033 & 0.014 & $0.186^{b}$ & $0.043^{\mathrm{a}}$ \\
\hline Waistline & $-0.080^{\mathrm{b}}$ & $0.037^{b}$ & $0.594^{b}$ & $0.630^{\mathrm{b}}$ & & $0.739^{b}$ & $0.175^{b}$ & $-0.244^{b}$ & 0.028 & 0.016 & $0.280^{\mathrm{b}}$ & $-0.042^{\mathrm{a}}$ \\
\hline Hipline & $-0.059^{b}$ & $0.142^{b}$ & $0.697^{b}$ & $0.682^{\mathrm{b}}$ & $0.704^{b}$ & & $0.129^{b}$ & $-0.232^{b}$ & 0.028 & 0.014 & $0.227^{b}$ & 0.024 \\
\hline FBG & $-0.352^{\mathrm{b}}$ & $-0.079^{b}$ & $0.146^{b}$ & $0.197^{b}$ & $0.247^{b}$ & $0.177^{\mathrm{b}}$ & & $-0.094^{b}$ & $0.088^{b}$ & $0.107^{\mathrm{b}}$ & $0.185^{b}$ & 0.036 \\
\hline HDL & $0.09 \mathrm{I}^{\mathrm{b}}$ & 0.004 & $-0.224^{b}$ & $-0.247^{b}$ & $-0.235^{b}$ & $-0.217^{b}$ & $-0.163^{b}$ & & $0.229^{b}$ & $0.349^{b}$ & $-0.38 I^{b}$ & 0.008 \\
\hline LDL & -0.002 & $-0.078^{\mathrm{b}}$ & $0.038^{b}$ & $0.086^{\mathrm{b}}$ & $0.072^{\mathrm{b}}$ & $0.049^{b}$ & $0.101^{\mathrm{b}}$ & $0.185^{b}$ & & $0.844^{b}$ & $0.106^{b}$ & -0.026 \\
\hline $\mathrm{TC}$ & -0.02 & $-0.088^{b}$ & 0.002 & $0.052^{b}$ & $0.037^{b}$ & $0.027^{b}$ & $0.119^{b}$ & $0.308^{b}$ & $0.866^{\mathrm{b}}$ & & $0.296^{b}$ & -0.04 \\
\hline TG & $-0.108^{b}$ & $-0.08 \mathrm{I}^{\mathrm{b}}$ & $0.223^{b}$ & $0.284^{b}$ & $0.267^{b}$ & $0.242^{\mathrm{b}}$ & $0.286^{b}$ & $-0.423^{b}$ & $0.20 \mathrm{I}^{\mathrm{b}}$ & $0.327^{b}$ & & $-0.102^{\mathrm{a}}$ \\
\hline Age & $-0.143^{b}$ & $-0.291^{\mathrm{b}}$ & 0.01 & $0.166^{b}$ & $0.269^{b}$ & $0.179^{b}$ & $0.264^{b}$ & $-0.060^{\mathrm{b}}$ & $0.182^{b}$ & $0.213^{b}$ & $0.224^{b}$ & \\
\hline
\end{tabular}

Notes: The values in the lower triangle are the Pearson's correlation coefficients for females. Pearson's correlation coefficients for males are listed in the upper triangle. $P<0.05$ was considered statistically significant. ${ }^{\mathrm{P}}<0.05$ and ${ }^{\mathrm{b}} \mathrm{P}<0.0 \mathrm{I}$.

Abbreviations: DM, diabetes mellitus; BMI, body mass index; FBG, fasting blood glucose; HDL, high-density lipoprotein; LDL, low-density lipoprotein; TC, total cholesterol; TG, triglyceride. 
substance, energy, and hormone metabolism. In addition to lowering BG, the liver can also raise BG by breaking down glycogen. Thus, the liver plays a pivotal role in BG regulation. In the present study, we found high prevalence of low HDL-C and high TG in T2DM patients, which is similar to and further demonstrates the findings from a previous study. ${ }^{23}$

Our present study further confirmed the finding from a previous study ${ }^{23}$ that the relationship between serum lipid profile deficiency and the incidence of T2DM could be closer than that between obesity/waistline and T2DM in Chinese subjects. In addition, abnormal BMI/waistline and lipid profile, especially HDL-C and TG together, increased the incidence of T2DM, suggesting the presence of an additive effect on T2DM risk.

\section{Conclusion}

To summarize, our study gives further insight into a comprehensive risk assessment for T2DM in Chinese people, increasing our understanding of the effect of waistline, BMI, and serum lipid profiles, including HDL-C, LDL-C, TC, and $\mathrm{TG}$, on T2DM. We found that waistline and BMI are key important variables relating to T2DM. There also appears to be significant abnormal lipid metabolism in T2DM patients, and the same is true for people who have deficient serum lipid levels, especially the level of HDL-C and TG. These variables and correlations that indicate metabolism deficiency should be used in an effort to prevent and reduce the effect of T2DM.

\section{Acknowledgments}

The authors wish to offer their sincere and grateful thanks to the subjects who helped with the development of their study. The authors also thank the staff who helped to measure the biochemical parameters in the Department of Clinical Laboratory in Dalian Central Hospital.

\section{Disclosure}

The authors report no conflicts of interest in this work.

\section{References}

1. An R. Prevalence and trends of adult obesity in the US, 1999-2012. ISRN Obes. 2014;2014:24-29.

2. Flegal KM, Carroll MD, Kit BK, Ogden CL. Prevalence of obesity and trends in the distribution of body mass index among US adults, 1999-2010. JAMA. 2012;307(5):491-497.

3. de Wilde JA, Zandbergen-Harlaar S, van Buuren S, Middelkoop BJ. Trends in body mass index distribution and prevalence of thinness, overweight and obesity in two cohorts of Surinamese South Asian children in The Netherlands. Arch Dis Child. 2013;98(4):280-285.

4. Ning XJ, Zhan CQ, Yang YH, et al. Secular trends in prevalence of overweight and obesity among adults in rural Tianjin, China from 1991 to 2011: a population-based study. PLoS One. 2014;9(12):5-16.
5. de Mutsert R, Sun Q, Willett WC, Hu FB, van Dam RM. Overweight in early adulthood, adult weight change, and risk of type 2 diabetes, cardiovascular diseases, and certain cancers in men: a cohort study. Am J Epidemiol. 2014;179(11):1353-1365.

6. Nora M, Guimaraes M, Almeida R, et al. Excess body mass index loss predicts metabolic syndrome remission after gastric bypass. Diabetol Metab Syndr. 2014;6:5-11.

7. Phillips LK, Prins JB. The link between abdominal obesity and the metabolic syndrome. Curr Hypertens Rep. 2008;10(2):156-164.

8. Haslam DW, James WPT. Obesity. Lancet. 2005;366(9492): 1197-1209.

9. Schulze MB, Bergmann MM, Heidemann C, Hoffmann K, Schienkiewitz A, Boeing H. Comparison of anthropoinetric characteristics in predicting the incidence of type 2 diabetes in the EPIC-potsdam study. Diabetes Care. 2006;29(8):1921-1923.

10. Shaw JTE, Purdie DM, Neil HAW, Levy JC, Turner RC. The relative risks of hyperglycaemia, obesity and dyslipidaemia in the relatives of patients with type II diabetes mellitus. Diabetologia. 1999;42(1): 24-27.

11. Pontiroli AE, Monti LD, Pizzini A, Piatti P. Familial clustering of arterial blood pressure, HDL cholesterol, and pro-insulin but not of insulin resistance and microalbuminuria in siblings of patients with type 2 diabetes. Diabetes Care. 2000;23(9):1359-1364.

12. Eckel RH, Grundy SM, Zimmet PZ. The metabolic syndrome. Lancet. 2005;365(9468):1415-1428.

13. Christensen K, Doblhammer G, Rau R, Vaupel JW. Ageing populations: the challenges ahead. Lancet. 2009;374(9696):1196-1208.

14. Hartemink N, Boshuizen HC, Nagelkerke NJD, Jacobs MAM, van Houwelingen HC. Combining risk estimates from observational studies with different exposure cutpoints: a meta-analysis on body mass index and diabetes type 2. Am J Epidemiol. 2006;163(11):1042-1052.

15. Ganz ML, Wintfeld N, Li Q, Alas V, Langer J, Hammer M. The association of body mass index with the risk of type 2 diabetes: a case-control study nested in an electronic health records system in the United States. Diabetol Metab Syndr. 2014;6:17-24.

16. Pischon T, Nothlings U, Boeing H. Obesity and cancer. Proc Nutr Soc. 2008;67(2):128-145.

17. Yusuf S, Hawken S, Ounpuu S, et al. Effect of potentially modifiable risk factors associated with myocardial infarction in 52 countries (the INTERHEART study): case-control study. Lancet. 2004; 364(9438):937-952.

18. Hauner H, Bramlage $\mathrm{P}$, Lösch C, et al. Overweight, obesity and high waist circumference regional differences in prevalence in primary medical care. Dtsch Arztebl Int. 2008;105(48):827-833.

19. Kuo JF, Hsieh YT, Mao IC, Lin SD, Tu ST, Hsieh MC. Association between body mass index and all-cause mortality in patients with type 2 diabetes mellitus a 5.5-year prospective analysis. Medicine. 2015; 94(34):e1398.

20. Pietzsch J, Julius U, Nitzsche S, Hanefeld M. In vivo evidence for increased apolipoprotein A-I catabolism in subjects with impaired glucose tolerance. Diabetes. 1998;47(12):1928-1934.

21. Moebus S, Hanisch JU, Aidelsburger P, Bramlage P, Wasem J, Jockel KH. Impact of 4 different definitions used for the assessment of the prevalence of the metabolic syndrome in primary healthcare: the German Metabolic and Cardiovascular Risk Project (GEMCAS). Cardiovasc Diabetol. 2007;6:85-94.

22. Grundy SM, Cleeman JI, Daniels SR, et al; American Heart Association; National Heart, Lung, and Blood Institute. Diagnosis and management of the metabolic syndrome - An American Heart Association/National Heart, Lung, and Blood Institute Scientific Statement. Circulation. 2005;112(17):2735-2752.

23. Li WD, Fu KF, Li GM, et al. Comparison of effects of obesity and nonalcoholic fatty liver disease on incidence of type 2 diabetes mellitus. World J Gastroenterol. 2015;21(32):9607-9613. 


\section{Publish your work in this journal}

Clinical Interventions in Aging is an international, peer-reviewed journal focusing on evidence-based reports on the value or lack thereof of treatments intended to prevent or delay the onset of maladaptive correlates of aging in human beings. This journal is indexed on PubMed Central, MedLine,

CAS, Scopus and the Elsevier Bibliographic databases. The manuscript management system is completely online and includes a very quick and fair peer-review system, which is all easy to use. Visit http://www.dovepress. com/testimonials.php to read real quotes from published authors.

Submit your manuscript here: http://www.dovepress.com/clinical-interventions-in-aging-journal 